\title{
Myostatin Increases Smad2 Phosphorylation and Atrogin-1 Expression in Chick Embryonic Myotubes
}

\author{
Takaoki Saneyasu, Kazuhisa Honda and Hiroshi Kamisoyama \\ Graduate School of Agricultural Science, Kobe University, Kobe 657-8501, Japan
}

\begin{abstract}
Skeletal muscle mass is an important trait in poultry meat production. In mammals, myostatin, a negative regulator of skeletal muscle growth, activates Smad transcription factors and induces the expression of atrogin-1 by regulating the Akt/FOXO pathway. Although the amino acid sequence of chicken myostatin is known to be completely identical to its mammalian counterpart, previous studies in chicken skeletal muscles have implied that the physiological roles of chicken myostatin are different from those of mammals. Furthermore, it remains to be elucidated whether myostatin affects cellular signaling factors and atrogin-1 expression. In this study, using chick embryonic myotubes, we found that myostatin significantly increased the phosphorylation rate of Smad2 and mRNA levels of atrogin-1. No significant change was observed in the phosphorylation of Akt and FOXO1. These in vitro results suggest that the molecular mechanisms underlying myostatin-induced expression of atrogin-1 might be different between chickens and mammals.
\end{abstract}

Key words: atrogin-1, chick myotube, myostatin, Smad

J. Poult. Sci., 56: 224-230, 2019

\section{Introduction}

Skeletal muscle mass is an important trait in poultry meat production. Since it is controlled by a balance between protein synthesis and degradation, a number of studies have been carried out to clarify the mechanisms underlying protein metabolism in poultry skeletal muscle.

Numerous lines of evidence indicate that Akt-mediated signaling pathways play critical roles in regulating protein synthesis and proteolysis in muscle cells (Glass, 2005; Sandri, 2008, 2013; Schiaffino et al., 2013; Sanchez et al., 2014). For example, activation of the Akt/mTOR pathway stimulates protein synthesis. The phosphorylated Akt directly phosphorylates and inactivates FOXO, which is a major transcription factor of atrophy-related genes, atrogenes, such as atrogin-1 and MuRF-1 (Foletta et al., 2011; Gumucio and Mendias, 2013). Atrogin-1 and MuRF-1, two musclespecific E3 ubiquitin ligases, induce the degradation of myofibril proteins. Therefore, the activation of Akt-mediated pathways and expression of atrogenes have been generally examined to understand protein metabolism in skeletal muscle.

Received: August 22, 2018, Accepted: November 12, 2018

Released Online Advance Publication: December 25, 2018

Correspondence: Takaoki Saneyasu, PhD., Department of Bioresource Science, Graduate School of Agricultural Science, Kobe University 1-1, Rokkodai-cho, Nada-ku, Kobe 657-8501, Japan.

(E-mail: saneyasu@phoenix.kobe-u.ac.jp)
Myostatin, a member of the transforming growth factor- $\beta$ (TGF- $\beta$ ) superfamily, has been demonstrated to inhibit muscle mass development in mammals (McPherron et al., 1997; Huang et al., 2011; Rodriguez et al., 2014). For example, individual muscles of myostatin null mice weigh 2-3 times more than those of wild-type mice, and the increase in skeletal muscle mass appears to result from a combination of hyperplasia and hypertrophy (McPherron et al., 1997). Naturally occurring mutation in the myostatin gene leads to a hypermuscular phenotype in humans, mice, dogs, sheep, and cattle (Rodriguez et al., 2014). In addition, myostatin plays a fundamental role in regulating adult muscle growth and size (Rodriguez et al., 2014).

Accumulating evidence from previous studies have revealed the manner in which myostatin affects skeletal muscle growth. For example, myostatin downregulates the Akt/ mTOR pathway and inhibits protein synthesis in $\mathrm{C} 2 \mathrm{C} 12$ myotubes and mammalian skeletal muscles (Taylor et al., 2001; Welle et al., 2006; Amirouche et al., 2009; Morissette et al., 2009; Lipina et al., 2010). A recent in vitro study showed that high concentrations $(2-3 \mu \mathrm{g} / \mathrm{mL})$ of myostatin significantly inhibited the mTOR pathway and protein synthesis, whereas low concentrations $(0.01-1 \mu \mathrm{g} / \mathrm{mL})$ of myostatin significantly induced the phosphorylation of AMPactivated protein kinase (AMPK) and inhibited protein synthesis without affecting the mTOR pathway (Deng et al., 2017). In addition to the inhibition of protein synthesis, myostatin promotes the transcription of atrogin-1 by regu- 
lating Smads and the Akt/FOXO pathway (Gumucio and Mendias, 2013; Lokireddy et al., 2011; McFarlane et al., 2006). Smads are transcription factors that are phosphorylated after myostatin binds to its receptors (Huang et al., 2011; Rodriguez et al., 2014). A previous in vivo study reported that $S$ mad3 was sufficient to induce an increase in atrogin-1 promoter activity in murine skeletal muscle that was co-transfected with Smad3 and atrogin-1 promoter (Goodman et al., 2013). However, several in vitro and in vivo studies have shown that myostatin inhibits protein synthesis and the Akt/mTOR pathway without affecting protein degradation and expression of atrogin-1 and MuRF1 (Taylor et al., 2001; Welle et al., 2006; Amirouche et al., 2009). Collectively, results suggest that myostatin inhibits skeletal muscle growth mainly by downregulating Akt phosphorylation in mammals.

The amino acid sequence of mature myostatin is identical among humans, mice, rats, pigs, dogs, chickens, and turkeys (Huang et al., 2011). However, previous studies have suggested that the roles of myostatin in skeletal muscles differ between mammals and chickens. For example, knockdown of the myostatin gene by RNA interference increased body, but not carcass, weight in chickens (Bhattacharya et al., 2017), and myostatin expression was not altered in lines of poultry exhibiting myofiber hyper- and hypoplasia (Mott and Ivarie, 2002). In contrast to the results from previous studies on mammalian skeletal muscles which showed that myostatin expression increased due to food deprivation or restriction (Allen et al., 2010; Zhao et al., 2016), myostatin mRNA levels decreased due to fasting in chicken skeletal muscles (Guernec et al., 2004; Saneyasu et al., 2015). Furthermore, it remains to be elucidated as to how myostatin affects the cellular signaling factors and expression of atrogenes in chicken skeletal muscle. To clarify the mechanism underlying species-specific roles of myostatin in chicken skeletal muscle, we investigated the effects of myostatin on the mRNA and protein levels of protein metabolism-related factors in chick embryonic myotubes.

\section{Materials and Methods}

\section{Cell Culture}

Breast muscles dissected from 14-day-old chick embryos were minced using surgical scissors and digested with HBSS (+) (Nacalai Tesque, Inc., Kyoto, Japan) containing 0.2\% collagenase (Worthington Biochemical Corp., Lakewood, NJ, USA) for $20 \mathrm{~min}$ at $37^{\circ} \mathrm{C}$. The cells were collected by centrifugation and resuspended in DMEM (Nacalai Tesque, Inc., Kyoto, Japan) supplemented with 15\% serum (Fetal Clone III, GE Healthcare Bio-Sciences AB, Uppsala, Sweden), $1 \times$ non-essential amino acid solution (Nacalai Tesque, Inc., Kyoto, Japan), and $1 \times$ gentamicin/amphotericin solution (Life Technologies, Carlsbad, CA, USA). The cell suspension was passed through a cell strainer to remove tissue debris and then transferred to an uncoated flask to allow attachment of fibroblasts. After $1 \mathrm{~h}$, the unattached cells were transferred to another uncoated flask and this procedure was repeated 2-3 times. The unattached cells were counted and plated onto collagen I-coated 12 -well plates at $1 \times 10^{5}$ cells/well. The cells were incubated in the medium described above at $37^{\circ} \mathrm{C}$, with $5 \% \mathrm{CO}_{2}$ in a humidified chamber until the formation of myotubes. Myotubes were treated with or without $20 \mathrm{nM}$ recombinant human/rat/mouse myostatin (PeptroTech Inc., Rocky Hill, NJ, USA) for $2 \mathrm{~h}$, in the absence or presence of serum.

\section{Real-time PCR Analysis}

The cells were washed with phosphate-buffered saline (PBS). Then, total RNA was extracted from the cells using Sepazol-RNA I (Nacalai Tesque, Inc., Kyoto, Japan). Firststrand cDNA was synthesized from total RNA using Rever Tra Ace ${ }^{\circledR}$ qPCR RT Master Mix with gDNA Remover (Toyobo Co. Ltd, Osaka, Japan). The levels of mRNA were quantified for each primer (Table 1) using TB Green Premix Ex Taq II (Tli RNaseH Plus; Takara Bio Inc., Otsu, Japan) according to the supplier's recommendations, in an Applied Biosystems 7300 Real-Time PCR System (Applied Biosystems, Foster City, CA, USA). The expression levels of target genes were normalized to that of ribosomal protein S17 (RPS17).

\section{Western Blot Analysis}

Western blot analysis was performed as previously described by Saneyasu et al. (2017). Briefly, cells were rinsed with ice-cold PBS. Then, cells were scraped into $100 \mu \mathrm{L}$ of lysis buffer. The cell lysates were ultrasonicated and centrifuged at $17,900 \times g$ for $15 \mathrm{~min}$ at $4^{\circ} \mathrm{C}$. The supernatants were stored at $-80^{\circ} \mathrm{C}$. Protein concentrations were determined using the Pierce BCA Protein Assay Kit (Pierce Biotechnology, Rockford, IL, USA). The lysates ( $4 \mu \mathrm{g}$ of protein) were subjected to sodium dodecyl sulfate-polyacryl-

Table 1. Primer sequences used for real-time PCR analysis

\begin{tabular}{llll}
\hline \hline Gene name & \multicolumn{1}{c}{ Forward primer } & Reverse primer & Accession number \\
\hline Atrogin-1 & $5^{\prime}$-cac ctt ggg aga agc ctt caa-3' & $5^{\prime}$-ccg gga gtc cag gat agc a-3' & NM_001030956 \\
FOXO1 & $5^{\prime}$-tct ggt cag gag gga at gg-3' & $5^{\prime}$-gct tgc agg cca ctt tga g-3' & NM_204328 \\
MuRF-1 & $5^{\prime}$-tgg aga aga ttg agc aag gct at-3' & $5^{\prime}$-gcg agg tgc tca aga ctg act-3' & XM_424369 \\
Myostatin & $5^{\prime}$-acc cac caa gat gtc ccc ta -3' & $5^{\prime}$-acc cgc aac gat cta caa cc-3' & NM_001001461 \\
RPS17 & $5^{\prime}$-gcg ggt gat cat cga gaa gt-3' & $5^{\prime}$-gcg ctt gtt ggt gtg aag t-3' & NM_204217 \\
\hline
\end{tabular}

FOXO, forkhead box class O; MuRF-1, muscle ring-finger protein 1; RPS17, ribosomal protein S17.

The primers of atrogin-1, FOXO1, MuRF-1, and RPS17 have been used in previous studies (Saneyasu et al., 2015, 2016, 2017). 
amide gel electrophoresis (SDS-PAGE) and western blotting using HorizeBlot (ATTO Co., Tokyo, Japan), according to the manufacturer's instructions. Bands were detected by Chemi-Lumi one Super (Nacalai Tesque, Inc., Kyoto, Japan), visualized with the LumiCube (Liponics Inc., Tokyo, Japan), and quantified using the CS Analyzer software (ATTO Co., Tokyo, Japan). Anti-Akt (\#9272), anti-phospho-Akt (pAkt) (Ser473) (\#9271), anti-pAMPK $\alpha$ (Thr172) (\#2531), antiAMPK $\alpha$ (\#2532), anti-FOXO1 (\#9454), anti-pFOXO1 (Ser 256) (\#9461), anti-pSmad2 (Ser465/467)/ Smad3 (ser423/ 425) (\#8828), anti-Smad2/3 (\#8685), anti- $\beta$-actin (\#4967), and horseradish peroxidase (HRP) -conjugated anti-rabbit IgG (\#7074) were purchased from Cell Signaling Technology (Danvers, MA, USA). The species cross-reactivity is described in the manufacturer's data sheet. Additionally, we confirmed with the manufacturer that each antigen sequence for $\# 2532$, \#8828, and \#8685 has $88 \%, 100 \%$, and $100 \%$ homology with that of chicken, respectively. When detecting pSmad2/3, FOXO1, and pFOXO1, antibodies were diluted with Can Get Signal (Toyobo Co. Ltd, Osaka, Japan). Statistical Analysis

Data were analyzed using the Dunnett's test or $t$-test. All statistical analyses were performed using Excel 2013 (Microsoft, USA), with Statcel 3 add-in software (OMS, Tokyo, Japan).

\section{Results}

Myostatin significantly induced phosphorylation of Smad2 and expression of FOXO1 and atrogin-1 in chick embryonic myotubes cultured in the presence of serum, whereas no significant change was observed in the phosphorylation of Smad3, Akt, AMPK, and FOXO1, and in mRNA levels of MuRF-1 (Fig. 1). Although FOXO1 mRNA levels significantly increased, FOXO1 protein levels did not significantly change (Fig. 1). These results suggest that myostatin upregulates the expression of atrogin-1 and FOXO1 via Smad activation in an Akt/FOXO1 and AMPK pathway-independent manner.

The treatment with serum-free medium significantly increased mRNA levels of myostatin, atrogin-1, and MuRF-1 in chick myotubes (Fig. 2A). AMPK phosphorylation was significantly induced by serum-free treatment, whereas Akt phosphorylation was significantly inhibited (Fig. 2B). Unexpectedly, no significant change was observed in Smad2 and FOXO1 phosphorylation (Fig. 2B). In addition, FOXO1 mRNA levels were significantly decreased by serum-free treatment (Fig 2A), although no significant change was observed in its protein levels (Fig. 2B). All these findings suggest that serum-free treatment upregulates transcription of myostatin, atrogin-1, and MuRF-1, possibly via AMPK activation.

Similar to the results observed in the presence of serum, myostatin significantly increased Smad2 phosphorylation and FOXO1 expression in chick myotubes cultured under serum-free conditions, and no significant change was observed in the phosphorylation of Smad3, Akt, and AMPK, and in mRNA levels of MuRF-1 (Fig. 2). Moreover, no significant change was observed in FOXO1 protein levels and its phosphorylation (Fig. 2A). However, no significant change was observed in atrogin-1 mRNA levels (Fig. 2A). These results suggest that Smad activation did not enhance serum-free-induced upregulation of atrogin-1 expression.

Myostatin mRNA levels were dramatically decreased by myostatin treatment under serum-free conditions (Fig. 2B). Similarly, although no significant difference was observed, mRNA levels of myostatin decreased to $58 \%$ in myostatintreated cells under serum-supplemented conditions (Supplementary Figure 1). Therefore, the present results suggest that myostatin expression is negatively regulated via myostatininduced Smad activation in chicken skeletal muscle.

\section{Discussion}

A previous in vitro study using $\mathrm{C} 2 \mathrm{C} 12$ myotubes showed that myostatin increases mRNA levels of FOXO1 and atrogin-1, but not MuRF-1 (McFarlane et al., 2006). Similarly, overexpression of activin receptor-like kinase 5 (which is activated by the binding of myostatin to an activin type II receptor and then phosphorylates Smads) or Smad3 increases the activity of atrogin-1 but not MuRF-1 promotor, in murine skeletal muscle (Goodman et al., 2013; Sartori et al., 2009). Smad3 can bind directly to DNA at the $5^{\prime}$-AAGAC- $3^{\prime}$ sequence known as Smad-binding element, whereas Smad2 cannot bind directly to DNA (Matsuzaki 2011). However, Sartori et al. (2009) showed that RNAi-mediated knockdown of Smad3 alone or of both Smad2 and Smad3 induces a 10\% and $22 \%$ increase in the cross-sectional area of murine muscle fiber, respectively. Smad2, therefore, also appears to be involved in the inhibition of muscle growth. In this study, using chick embryonic myotubes, similar results were observed, except Smad3 phosphorylation. These findings therefore suggest that the myostatin/Smad pathway plays a role in regulating the expression of proteolysis-related factors in chicken skeletal muscles, but the contributing isoform may be different from that in mammalian ones.

Previous studies using mammalian cells have investigated the long-term (12-48 h) effects of myostatin (McFarlane et al., 2006; Deng et al., 2017; Lokireddy et al., 2011). McFarlane et al. (2006) showed that myostatin-induced promotion of atrogin-1 expression is dependent on FOXO1. Additionally, Lokireddy et al. (2011) found that active Smad signaling is required for myostatin to increase the protein levels of FOXO1 and atrogin-1. In contrast, the present study investigated the relatively short-term $(2 \mathrm{~h})$ effects of myostatin. Therefore, the difference in incubation time might be one of the reasons why no significant change was observed in the levels of Akt and FOXO1. Importantly, the present study showed that myostatin induced Smad2 phosphorylation and atrogin-1 expression without affecting the Akt/FOXO1 pathway. Smads are known to cooperate with other DNA binding proteins to elicit specific transcriptional response (Shi and Massagué, 2003). For example, Smad2/3 can bind members of the FOXO family of transcription factors to regulate gene expression (Gumucio and Mendias, 2013). Therefore, the present results might provide new 
A
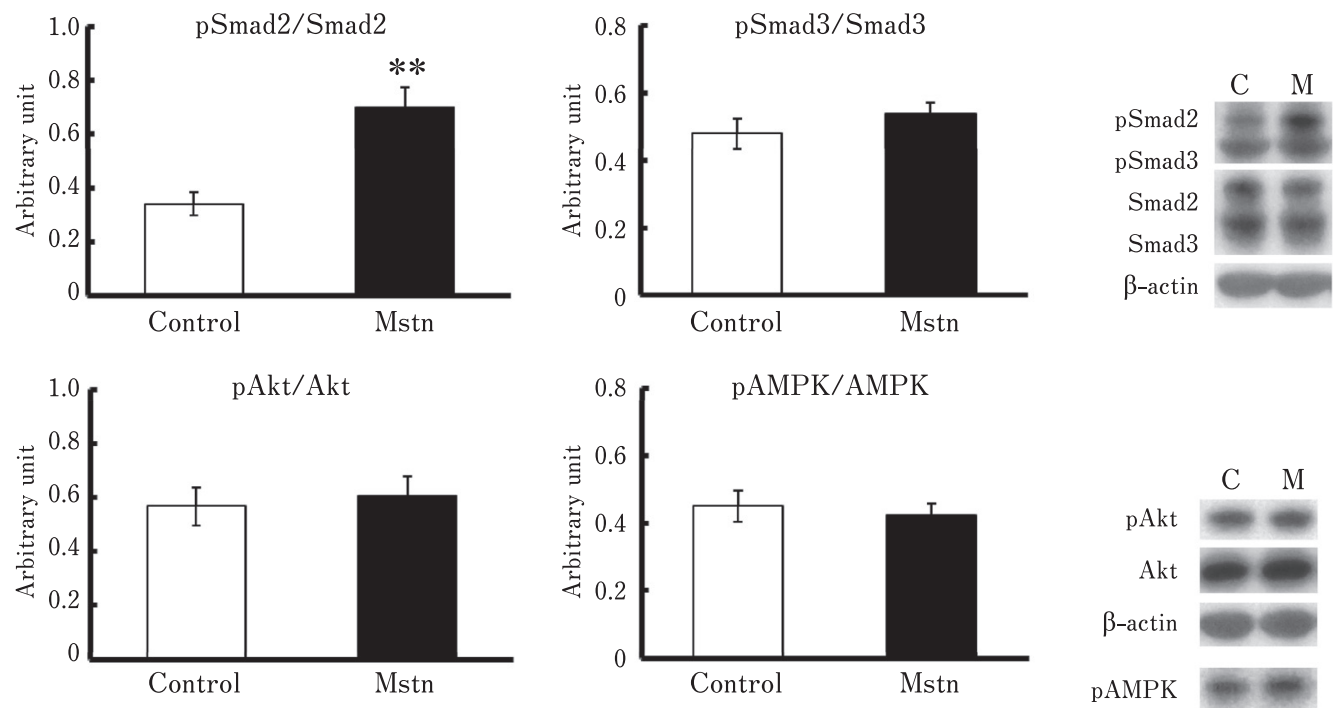

C M

pAkt

Akt

$\beta$-actin

pAMPK
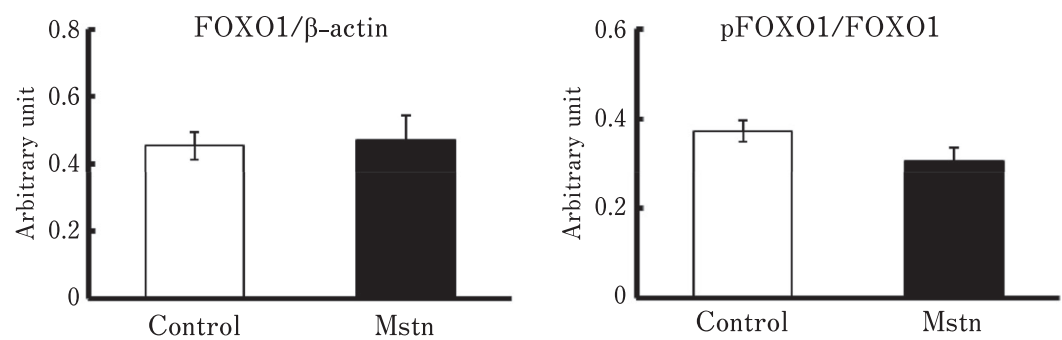

AMPK

$\beta$-actin

pFOXO1

FOXO1

$\beta$-actin

B
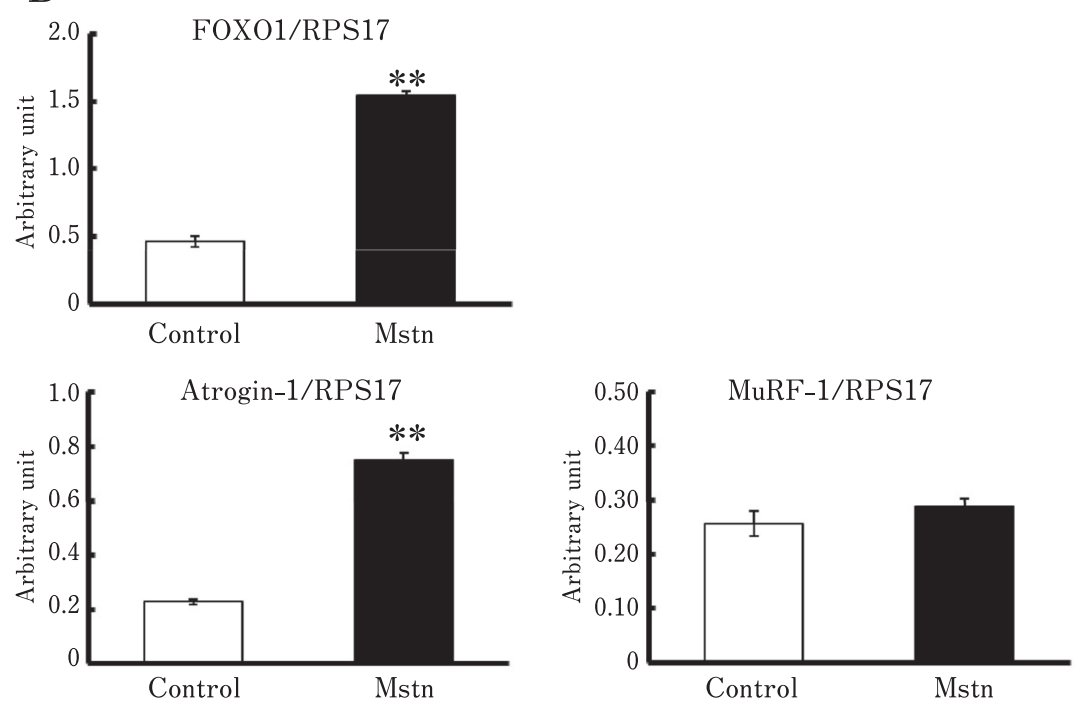

Fig. 1. (A) Effects of myostatin on the phosphorylation of Smad, Akt, FOXO1, and AMPK, (B) Effects of myostatin on the mRNA levels of FOXO1, atrogin-1, and MuRF-1, in the chick myotubes. The myotubes were treated with $15 \%$ serum-containing medium with or without (Con) $20 \mathrm{nM}$ myostatin (Mstn), for $2 \mathrm{~h}$. Data are expressed as mean \pm standard error of the mean of five (A) and six (B) wells in each group. Student's $t$-test was used to analyze the differences. $* *$ Significant with respect to control group $(* * P<0.01)$. 

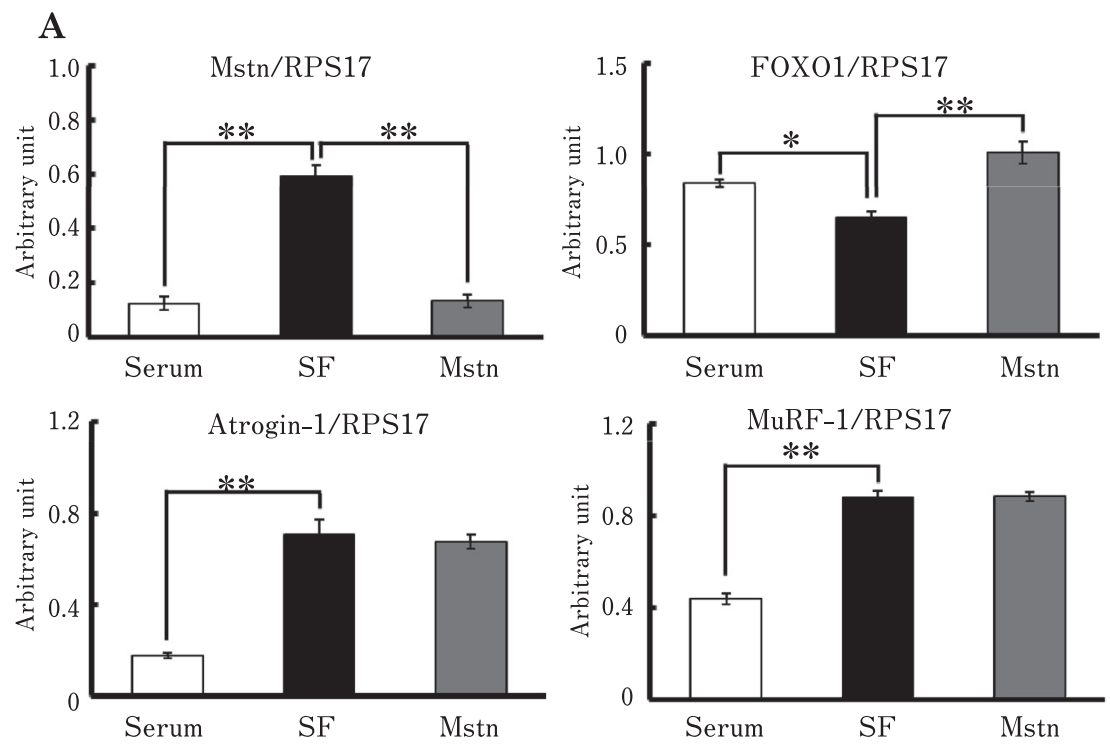

\section{B}
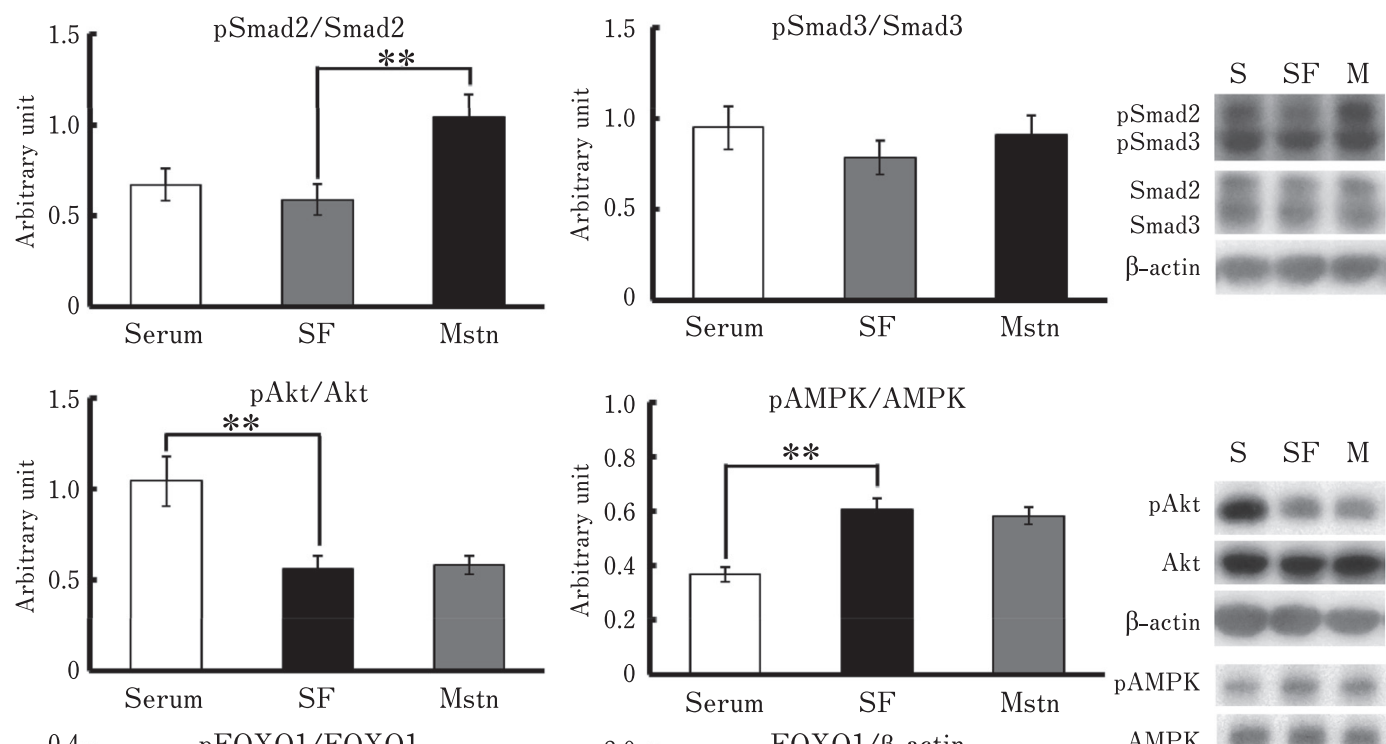

S SF M
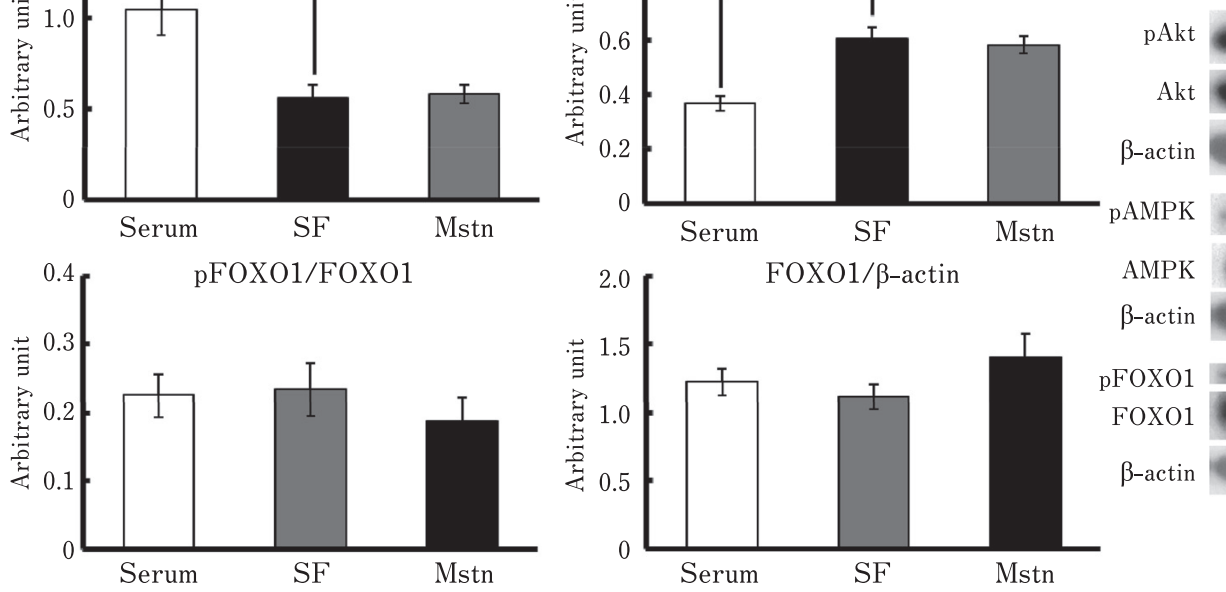

AMPK

$\beta$-actin

pFOXO1

FOXO1

$\beta$-actin

Fig. 2. (A) Effects of serum-free conditions and myostatin treatment on the mRNA levels of myostatin, FOXO1, atrogin-1, and MuRF-1, (B) Effects of serum-free conditions and myostatin treatment on the phosphorylation of Smad, Akt, FOXO1, and AMPK, in the chick myotubes. The myotubes were treated with either $15 \%$ serum-containing medium (Serum), serum-free medium (SF) with or without $20 \mathrm{nM}$ myostatin (Mstn), for $2 \mathrm{~h}$. Data are expressed as mean \pm standard error of the mean of six wells in each group. The Dunnett's test was used to analyze the differences between SF and Serum or Mstn groups. *,** Significant with respect to SF group $(* P<0.05 ; * * P<0.01)$. 
hypotheses, suggesting that Smads are able to promote atrogin-1 transcription in cooperation with FOXO1 independently of Akt-mediated regulation, and that Smad cooperates with other unknown factors to regulate atrogin-1 expression.

Serum-free treatment increases mRNA and protein levels of atrogin-1 and MuRF-1 and decreases phosphorylation of Akt and FOXO in $\mathrm{C} 2 \mathrm{C} 12$ and L6 myotubes (Kim et al., 2015; Sandri et al., 2004), indicating that the increase in atrogin-1 and MuRF-1 expression is controlled by the Akt/ FOXO pathway. However, a previous study in $\mathrm{C} 2 \mathrm{C} 12$ myotubes showed that an AMPK activator increased atrogin1 and MuRF-1 mRNA levels without affecting Akt phosphorylation (Egawa et al., 2014). In the present study, phosphorylation of AMPK, but not of FOXO1, was significantly induced by serum-free treatment with the increase in atrogin1 and MuRF-1 expression. Therefore, it is possible that AMPK regulates atrogin-1 and MuRF-1 expression without affecting the Akt/FOXO pathway in both mammals and birds.

An AMPK activator reportedly increased the levels of myostatin protein in L6 myotubes (Lee et al., 2015). Levels of myostatin mRNA significantly increased in skeletal muscles of Smad3-null mice and in C2C12 myotubes treated with a Smad3 inhibitor (McFarlane et al., 2014). In the present study, AMPK appeared to increase myostatin expression in chick myotubes, whereas Smad appeared to inhibit myostatin expression even when AMPK was activated. Therefore, these findings suggest that AMPK and Smad control myostatin expression in chicken myotubes cultured in vitro, in the same manner as seen in mammals. In contrast to the results from in vitro studies, previous in vivo studies have suggested a different mechanism for myostatin expression in the skeletal muscle, between mammals and chickens. Fasting significantly promoted myostatin expression in mice (Allen et $a l ., 2010$ ) and inhibited its expression in chickens (Guernec et al., 2004; Saneyasu et al., 2015). Although the exact reason for this difference remains unknown, based on the present results, fasting-induced decrease in myostatin expression in chicken skeletal muscle might be caused by the activation of the Smad signaling pathway. Interestingly, a previous study found that myostatin is present extracellularly in murine skeletal muscle as uncleaved pro-myostatin and proposed that extracellular cleavage of pro-myostatin to mature myostatin represents a novel control point for myostatin signaling in the skeletal muscle (Anderson et al., 2008). With respect to TGF- $\beta$, activation of latent complexes is being increasingly recognized as a critical step in the control of TGF- $\beta$ activity (Hayashi and Sakai, 2012). Indeed, in intact adult tissues and organs, TGF- $\beta$ is secreted in a biologically inactive (latent) form associated in a non-covalent complex with the extracellular matrix, and the expression of TGF- $\beta$ mRNA and protein levels do not often correlate with active TGF- $\beta$ levels (Hayashi and Sakai, 2012). It is therefore possible that fasting affects the activation of latent myostatin in chicken skeletal muscle and then the increase in the active form inhibits its expression via upregulation of
Smad phosphorylation.

The present study showed a discrepancy in atrogin-1 expression between the serum-supplemented and serum-free conditions. Although the exact reason is unclear, one possible explanation is that Smad-mediated upregulation of atrogin-1 might be limited under conditions of low AMPK activity in chick myotubes and as shown in the present study, this could be because myostatin induced Smad2 phosphorylation, but did not upregulate atrogin-1 expression under conditions of the high phosphorylation rate of AMPK, induced by serum-free treatment. Another possible explanation is that growth factors in the serum influence Smadmediated gene transcription. Further studies are required to clarify the molecular mechanism underlying myostatin/ Smad-induced transcription of atrogin-1.

In summary, significant increase was observed in Smad2 phosphorylation and atrogin-1 mRNA levels in myostatintreated chick myotubes, whereas no significant change was observed in the phosphorylation of Akt and FOXO1, and MuRF-1 mRNA levels. These results suggest that myostatin upregulates atrogin-1 transcription by Smad activation in an Akt/FOXO pathway-independent manner in chicken skeletal muscles, which might be different from the mechanism observed in mammalian skeletal muscles.

\section{Acknowledgment}

This work was supported by Kieikai Research Foundation.

\section{References}

Allen DL, Cleary AS, Lindsay SF, Loh AS and Reed JM. Myostatin expression is increased by food deprivation in a musclespecific manner and contributes to muscle atrophy during prolonged food deprivation in mice. Journal of Applied Physiology, 109: 692-701. 2010.

Amirouche A, Durieux AC, Banzet S, Koulmann N, Bonnefoy R, Mouret C, Bigard X, Peinnequin A and Freyssenet D. Downregulation of $\mathrm{Akt} / \mathrm{mammalian}$ target of rapamycin signaling pathway in response to myostatin overexpression in skeletal muscle. Endocrinology, 150: 286-294. 2009.

Anderson SB, Goldberg AL and Whitman M. Identification of a novel pool of extracellular pro-myostatin in skeletal muscle. Journal of Biological Chemistry, 283: 7027-7035. 2008.

Bhattacharya TK, Shukla R, Chatterjee RN and Dushyanth K. Knock down of the myostatin gene by RNA interference increased body weight in chicken. Journal of Biotechnology, 241: 61-68. 2017.

Deng Z, Luo P, Lai W, Song T, Peng J and Wei HK. Myostatin inhibits eEF2K-eEF2 by regulating AMPK to suppress protein synthesis. Biochemical and Biophysical Research Communications, 494: 278-284. 2017.

Egawa T, Ohno Y, Goto A, Ikuta A, Suzuki M, Ohira T, Yokoyama S, Sugiura T, Ohira Y, Yoshioka T and Goto K. AICARinduced activation of AMPK negatively regulates myotube hypertrophy through the HSP72-mediated pathway in $\mathrm{C} 2 \mathrm{C} 12$ skeletal muscle cells. American Journal of Physiology. Endocrinology and Metabolism, 306: E344-E354. 2014.

Foletta VC, White LJ, Larsen AE, Léger B and Russell AP. The role and regulation of MAFbx/atrogin-1 and MuRF1 in skeletal muscle atrophy. Pflügers Archiv, 61: 325-335. 2011. 
Glass, DJ. Skeletal muscle hypertrophy and atrophy signaling pathways. International Journal of Biochemistry \& Cell Biology, 37: 1974-1984. 2005.

Goodman CA, McNally RN, Hoffmann FM and Hornberger TA. Smad3 induces atrogin-1, inhibits mTOR and protein synthesis, and promotes muscle atrophy in vivo. Molecular Endocrinology, 27: 1946-1957. 2013.

Gumucio JP and Mendias CL. Atrogin-1, MurF-1, and sarcopenia. Endocrine, 43: 12-21. 2013.

Guernec A, Chevalier B and Duclos MJ. Nutrient supply enhances both IGF-1 and MSTN mRNA levels in chicken skeletal muscle. Domestic Animal Endocrinology, 26: 143-154. 2004.

Hayashi $\mathrm{H}$ and Sakai T. Biological significance of local TGF- $\beta$ activation in liver diseases. Frontiers in Physiology, 3: 12. 2012.

Huang Z, Chen X and Chen D. Myostatin: A novel insight into its role in metabolism, signal pathways, and expression regulation. Cellular Signaling, 23: 1441-1446. 2011.

Kim J, Won KJ, Jung SH, Lee KP, Shim SB, Kim MY, Kim JH, Lee $\mathrm{JU}$ and Kim B. DJ-1 protects against undernutrition-induced atrophy through inhibition of the MAPK-ubiquitin ligase pathway in myoblasts. Life Science, 143: 50-57. 2015.

Lee K, Ochi E, Song H and Nakazato K. Activation of AMPactivated protein kinase induce expression of FoxO1, FoxO3, and myostatin after exercise-induced muscle damage. Biochemical and Biophysical Research Communications, 466: 289-294. 2015.

Lipina C, Kendall H, McPherron AC, Taylor PM and Hundal HS. Mechanisms involved in the enhancement of mammalian target of rapamycin signalling and hypertrophy in skeletal muscle of myostatin-deficient mice. FEBS Letters, 584: 2403-2408.

Lokireddy S, Mouly V, Butler-Browne G, Gluckman PD, Sharma M, Kambadur R and McFarlane C. Myostatin promotes the wasting of human myoblast cultures through promoting ubiquitinproteasome pathway-mediated loss of sarcomeric proteins. American journal of physiology. Cell physiology, 301: C1316C1324. 2011.

Matsuzaki K. Smad phosphoisoform signaling specificity: the right place at the right time. Carcinogenesis, 32: 1578-1588. 2011.

McFarlane C, Plummer E, Thomas M, Hennebry A, Ashby M, Ling N, Smith H, Sharma M and Kambadur R. Myostatin induces cachexia by activating the ubiquitin proteolytic system through an NF-kappaB-independent, FoxO1-dependent mechanism. Journal of Cellular Physiology, 209: 501-14. 2006.

McFarlane C, Vajjala A, Arigela H, Lokireddy S, Ge X, Bonala S, Manickam R, Kambadur R and Sharma M. Negative autoregulation of myostatin expression is mediated by $\mathrm{Smad} 3$ and microRNA-27. PLoS One, 9: e87687. 2014.

McPherron AC, Lawler AM and Lee S. Regulation of skeletal muscle mass in mice by a new TGF- $\beta$ superfamily member. Nature, 387: 83-90. 1997.

Morissette MR, Cook SA, Buranasombati C, Rosenberg MA and Rosenzweig A. Myostatin inhibits IGF-I-induced myotube hypertrophy through Akt. American journal of physiology. Cell physiology, 297: C1124-C1132. 2009.

Mott I and Ivarie R. Expression of myostatin is not altered in lines of poultry exhibiting myofiber hyper- and hypoplasia. Poultry
Science, 81: 799-804. 2002.

Rodriguez J, Vernus B, Chelh I, Cassr-Malek I, Gabillard JC, Hadj Sassi A, Seiliez I, Picard B and Bonnieu A. Myostatin and the skeletal muscle atrophy and hypertrophy signaling pathways. Cellular and Molecular Life Sciences, 71: 4361-4371. 2014.

Sanchez AMJ, Candau RB and Bernardi H. FoxO transcription factors: their roles in the maintenance of skeletal muscle homeostasis. Cell and Molecular Life Sciences, 71: 16571671. 2014.

Sandri M. Protein breakdown in muscle wasting: Role of autophagylysosome and ubiquitin-proteasome. International Journal of Biochemistry \& Cell Biology, 45: 2121-2129. 2013.

Sandri M. Signaling in muscle atrophy and hypertrophy. Physiology, 23: 160-170. 2008.

Sandri M, Sandri C, Gilbert A, Skurk C, Calabria E, Picard A, Walsh K, Schiaffino S, Lecker SH and Goldberg AL. Foxo transcription factors induce the atrophy-related ubiquitin ligase atrogin-1 and cause skeletal muscle atrophy. Cell, 117: 399412. 2004.

Saneyasu T, Inui M, Kimura S, Yoshimoto Y, Tsuchii N, Shindo H, Honda $\mathrm{K}$ and Kamisoyama $\mathrm{H}$. The IGF-1/Akt/S6 signaling pathway is age-dependently downregulated in chicken breast muscle. Journal of Poultry Science, 53: 213-219. 2016.

Saneyasu T, Tsuchii N, Nakano Y, Kitashiro A, Tsuchihashi T, Shindo H, Honda K and Kamisoyama H. Effects of short-term fasting on the Akt-mediated pathway involved in protein metabolism in chicken skeletal muscle. Domestic Animal Endocrinology, 61: 54-61. 2017.

Saneyasu T, Kimura S, Inui M, Yoshimoto Y, Honda $\mathrm{K}$ and Kamisoyama H. Differences in the expression of genes involved in skeletal muscle proteolysis between broiler and layer chicks during food deprivation. Comparative Biochemistry and Physiology Part B Biochemistry \& Molecular Biology, 186: 36-42. 2015.

Sartori R, Milan G, Patron M, Mammucari C, Blaauw B, Abraham $\mathrm{R}$ and Sandri M. Smad2 and 3 transcription factors control muscle mass in adulthood. American journal of physiology. Cell physiology, 296: C1248-C1257. 2009.

Schiaffino S, Dyer KA, Cicilot S, Blaauw B and Sandi M. Mechanisms regulating skeletal muscle growth and atrophy. FEBS Journal, 280: 4294-4314. 2013.

Shi Y and Massagué J. Mechanisms of TGF- $\beta$ signaling from cell membrane to the nucleus. Cell, 113: 685-700. 2003.

Taylor WE, Bhasin S, Artaza J, Byhower F, Azam M, Willard DH Jr, Kull FC Jr and Gonzalez-Cadavid N. Myostatin inhibits cell proliferation and protein synthesis in $\mathrm{C} 2 \mathrm{C} 12$ muscle cells. American Journal of Physiology. Endocrinology and Metabolism, 280: E221-E228. 2001.

Welle S, Bhatt K and Pinkert CA. Myofibrillar protein synthesis in myostatin-deficient mice. American Journal of Physiology. Endocrinology and Metabolism, 290: E409-E415. 2006.

Zhao JX, Liu XD, Li K, Liu WZ, Ren YS and Zhang JX. Different dietary energy intake affects skeletal muscle development through an Akt-dependent pathway in Dorper $\times$ Small ThinTailed crossbred ewe lambs. Domestic Animal Endocrinology, 57: 63-70. 2016. 